九州大学学術情報リポジトリ

Kyushu University Institutional Repository

\title{
A remote surgery experiment between Japan and Thai land over Internet using a low latency CODEC system
}

Arata, Jumpei

Nagoya Institute of Technology

Takahashi, Hiroki

The University of Tokyo

Pitakwatchara, Phongsaen

The University of Tokyo

War isawa, Shin' ichi

The University of Tokyo

他

http://hdl. handle. net/2324/8529

出版情報: Proceedings of the IEEE International Conference on Robotics and Automation. 2007, pp. 953-959, 2007-04. IEEE

バージョン:

権利関係 : (c) IEEE 


\title{
A remote surgery experiment between Japan and Thailand over Internet using a low latency CODEC system
}

\author{
Jumpei Arata*, Hiroki Takahashi ${ }^{\dagger}$, Phongsaen Pitakwatchara ${ }^{\dagger}$, Shin’ichi Warisawa ${ }^{\dagger}$, Kazuo Tanoue ${ }^{\ddagger}$, \\ Kozo Konishi ${ }^{\ddagger}$, Satoshi Ieiri ${ }^{\ddagger}$, Shuji Shimizu, ${ }^{\ddagger}$, Naoki Nakashima ${ }^{\ddagger}$, Koji Okamura ${ }^{\ddagger}$, Yuichi Fujino ${ }^{\S}$, \\ Yukihiro Ueda", Pornarong Chotiwan", Mamoru Mitsuishi ${ }^{\dagger}$ and Makoto Hashizume ${ }^{\ddagger}$ \\ *Nagoya Institute of Technology, Gokiso-cho, Showa-ku, Nagoya, 466-8555, Japan, \\ Email: jumpei@nitech.ac.jp \\ ${ }^{\dagger}$ The University of Tokyo, 7-3-1 Hongo, Tokyo 113-8656, Japan \\ ${ }^{\ddagger}$ Kyushu University, 34-1 Maidashi, Higashi-ku, Fukuoka 812-8582, Japan

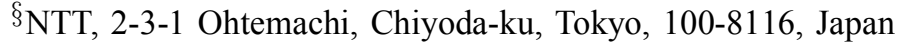 \\ ฯNTT Communications, 1-6 Uchisaiwai-cho 1-chome Chiyoda-ku, Tokyo, 100-8019, Japan \\ ${ }_{\text {Chulalongkorn University, Bangkok 10330, Thailand }}$
}

\begin{abstract}
Remote surgery is one of the most desired applications in the context of recent advanced medical technologies. For a future expansion of remote surgery, it is important to use conventional network infrastructures such as Internet. However, using such conventional network infrastructures, we are confronting time-delay problems of data transmission. In this paper, a remote surgery experiment between Japan and Thailand using a Research and Development Internet is presented. In the experiment, the image and audio information was transmitted by a newly developed low latency CODEC system to shorten the time-delay. By introducing the low latency CODEC system, the time-delay was shortened compared with the past remote surgery experiments despite the longer distance. We also conducted several network measurements such as a comparison between TCP/IP and UDP/IP about the control signal transmission.
\end{abstract}

\section{INTRODUCTION}

MIS (Minimally Invasive Surgery) technology is one of the most desired technologies from the aspect of QOL (Quality Of Life). MIS is well-known that it reduces patient's physical burden, duration of hospital stays and medical cost. There are lots of studies about robotic system for MIS applications nowadays, including commercialized products such as da Vinci and ZEUS[2]-[12]. We have developed a minimally invasive surgical system for dexterity extension of surgeons and capability of remote surgery[13]-[16]. The master slave dexterous manipulator allows dexterity to be increased. Moreover, with the capability of remote surgery, it is possible to realize participations of highly capable doctors to a surgery, which takes place in a distant place. And also, it is possible to facilitate a team work medical treatment between doctors from all around the world.

Marescaux, et al. have conducted a remote surgery by using a surgical robot ZEUS through a dedicated fiberoptic line between New York and Strasbourg[1]. However, it is generally costly for laying dedicated fiber-optic lines and running them (e.g. Remote surgery facilities must be connected by an exclusive fiber-optic line each other). Thus the use of conventional network infrastructures is preferable for the future expansion of remote surgery applications.
From these perspectives, we have conducted several times of remote surgery experiments by using conventional network infrastructures (ISDN $(2 B+D)$, ISDN $(23 B+D)$ and Research \& Development Internet). Firstly, we have conducted Japan inland remote surgery experiments between Tokyo and Shizuoka over $150 \mathrm{~km}$ in direct distance. ISDN $(2 \mathrm{~B}+\mathrm{D})$ and $\operatorname{ISDN}(23 \mathrm{~B}+\mathrm{D})$ have been used in the experiments, because ISDN is the most widely used network infrastructure among Japanese hospital facilities. Laparoscopic cholecystectomies have been successfully carried out on pigs in these experiments. The completion time of whole surgical procedure was approximately $90 \mathrm{~min}$ (including set-up time), which is roughly equal to conventional laparoscopic cholecystectomies. Using $\operatorname{ISDN}(2 \mathrm{~B}+\mathrm{D})$, the round-trip time-delay of control and of image in average were $99.8 \mathrm{~ms}$ and 676.0 ms respectively. Using $\operatorname{ISDN}(23 \mathrm{~B}+\mathrm{D})$, the round-trip timedelay of control and of image were $35.6 \mathrm{~ms}$ and $785.0 \mathrm{~ms}$ respectively. Secondly, we have conducted a transnational remote surgery experiment between Japan and Korea by using Research \& Development Internet testbet, APII (Asia-Pacific Information Infrastructure), which consists of an optical submarine cable network. A laparoscopic cholecystectomy was successfully carried out on a pig in the experiment. The round-trip time-delays of control signal and images were $13.0 \mathrm{~ms}$ and $871.0 \mathrm{~ms}$ respectively.

In this paper, a remote surgery experiment, which was conducted between Japan and Thailand using the low latency CODEC system is described. JGN2 (Japan Gigabit Network 2 ), which is a research and development network testbed was used for connecting between Japan and Thailand. Also, a newly developed low latency CODEC system was used in this experiment. The aims of the experiment were to examine the feasibility of a remote surgery using Internet and to study a comparison of effect caused by network data transmission in different network infrastructures.

\section{Minimally INVASIVE SURGiCAL SySteM}

The developed system consists of an operation site, a surgery site, and a communication link. The operation site is 

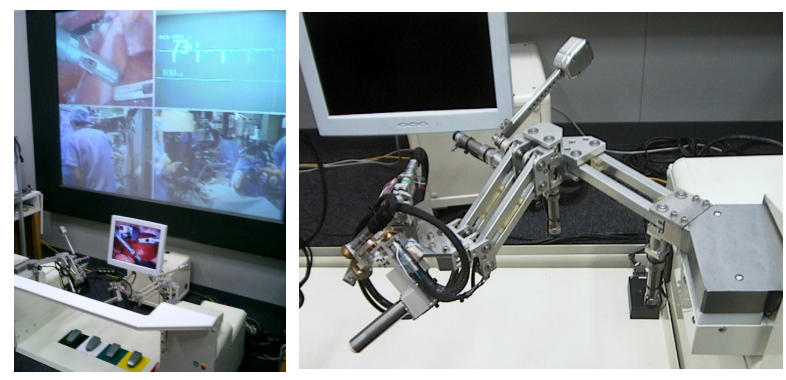

Fig. 1. Master manipulator

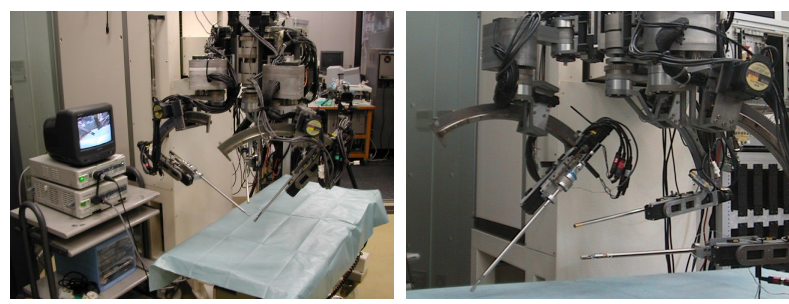

Fig. 2. Slave manipulator
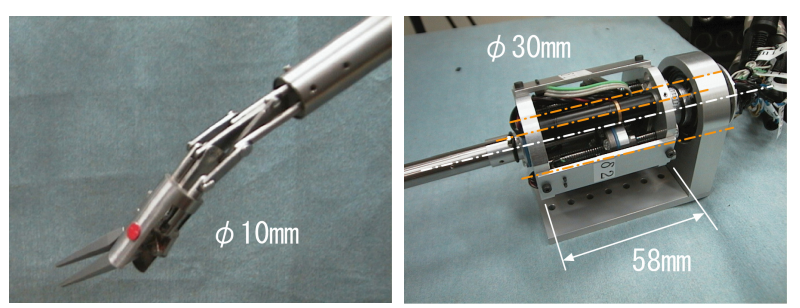

Fig. 3. Link driven multiple DOF forceps

where an operator and a master manipulator are located. The surgery site is where a patient, a medical assistant and a slave manipulator are located. These two sites can be connected by IP network (e.g. ISDN, LAN and ATM) for sending and receiving information such as image information, audio information and control signal of the manipulators. These manipulators are controlled by real-time controllers, and their local control frequencies were set as $1 \mathrm{kHz}$.

In the operation site, the master manipulator, a small display close to the operator, a large display behind the small display and foot switches are located. The operator sends position and orientation information to the surgery site by operating the master manipulator. The transmitted laparoscopic image is displayed on the display close to the operator (Fig.1). The developed master manipulator consists of right and left arms. Each arm has 7-DOF: 3 translational, 3 rotational, and a grasping motion.

In the surgery site, the slave manipulator (Fig.2) performs surgical operation by following the control signal received from the operation site. The slave manipulator consists of 3 arms: the left and right arms hold the robotic forceps and the middle arm holds a laparoscope. Each arm is designed to hold the insert position of trocar as a mechanical fixed point for the safety of patients. Therefore, the system ensures the patient's safety mechanically. The link driven multiple DOF bending forceps were designed as a part of the minimally invasive surgical system in order to realize complex tasks in an abdominal cavity (Fig.3)[15].

\section{LOW LATENCY CODEC SYSTEM}

In the past remote surgery experiments, the most of timedelay was caused by image and audio transmission. Because the image and audio information consists of relatively large data comparing with the control signal. By using MPEG CODEC, the transmitted data size can be smaller, however, the data processing time for MPEG compression and decompression is time-consuming. The low latency CODEC was developed in order to shorten the time-delay by a high speed image compression process.

The encoder of the low latency CODEC system, MP2000 consists of a MPEG2 encoder board SC2010E (NTT Electronics) and an IP communication module. SC2010E is an encoder board for lip-sync and real-time video/audio encoding. It is 4:2:2P@ML compatible and equipped with a variable noise filter. The encoding latencies (in local) by MP@ML and SP@ML are 117.5 ms and 70 ms respectively. Using the SC2010E, analog video and audio (PAL/NTSC) input is encoded to MPEG2. Then the encoder outputs the encoded MPEG2 TS data to DVB-SPI interface and to Ethernet interface as UDP data. The encoder configuration is shown in Fig.4, Table I shows the specifications of the encoder. As a decoder of the CODEC system, a conventional MPEG2 decoder RR1000D (NTT Electronics) was used.

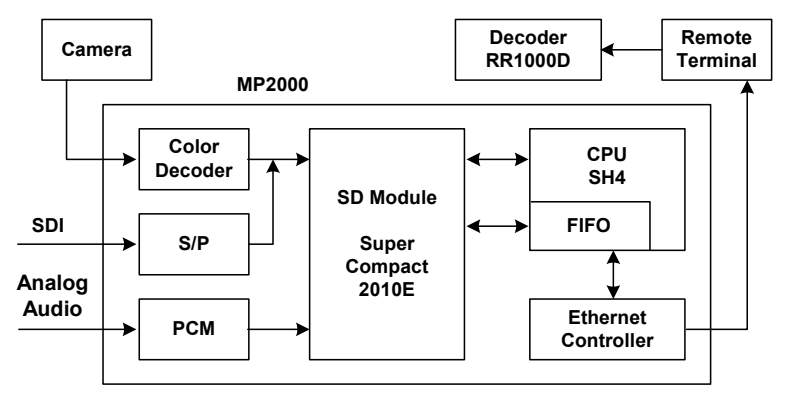

Fig. 4. Low latency CODEC system

TABLE I

SPECIFICATION OF THE LOW LATENCY CODEC SySTEM

\begin{tabular}{l|l}
\hline Image input & $\begin{array}{l}\text { NTSC/PAL, Composite / S-Video, } \\
\text { SDI (Option) }\end{array}$ \\
\hline $\begin{array}{l}\text { Image } \\
\text { compression }\end{array}$ & $422 \mathrm{P} @$ ML/MP@ML/SP@ML \\
\hline Audio input & Analog, Stereo \\
\hline $\begin{array}{l}\text { Audio } \\
\text { compression }\end{array}$ & MPEG1-Audio Layer2 \\
\hline $\begin{array}{l}\text { Multiplexing } \\
\text { scheme }\end{array}$ & TS \\
\hline TS output rate & $\begin{array}{l}\text { 2-54 Mbps (SPI,ASI), 2-18 Mbps } \\
\text { (Ether) }\end{array}$ \\
\hline Output & $\begin{array}{l}\text { UDP, DVB-SPI, DVB-ASI (Op- } \\
\text { tion) }\end{array}$ \\
\hline Packet format & TS/UDP \\
\hline Transmission & multicast/unicast communication \\
\hline Ethernet & 100 BaseTX full duplex, RJ45 \\
\hline
\end{tabular}




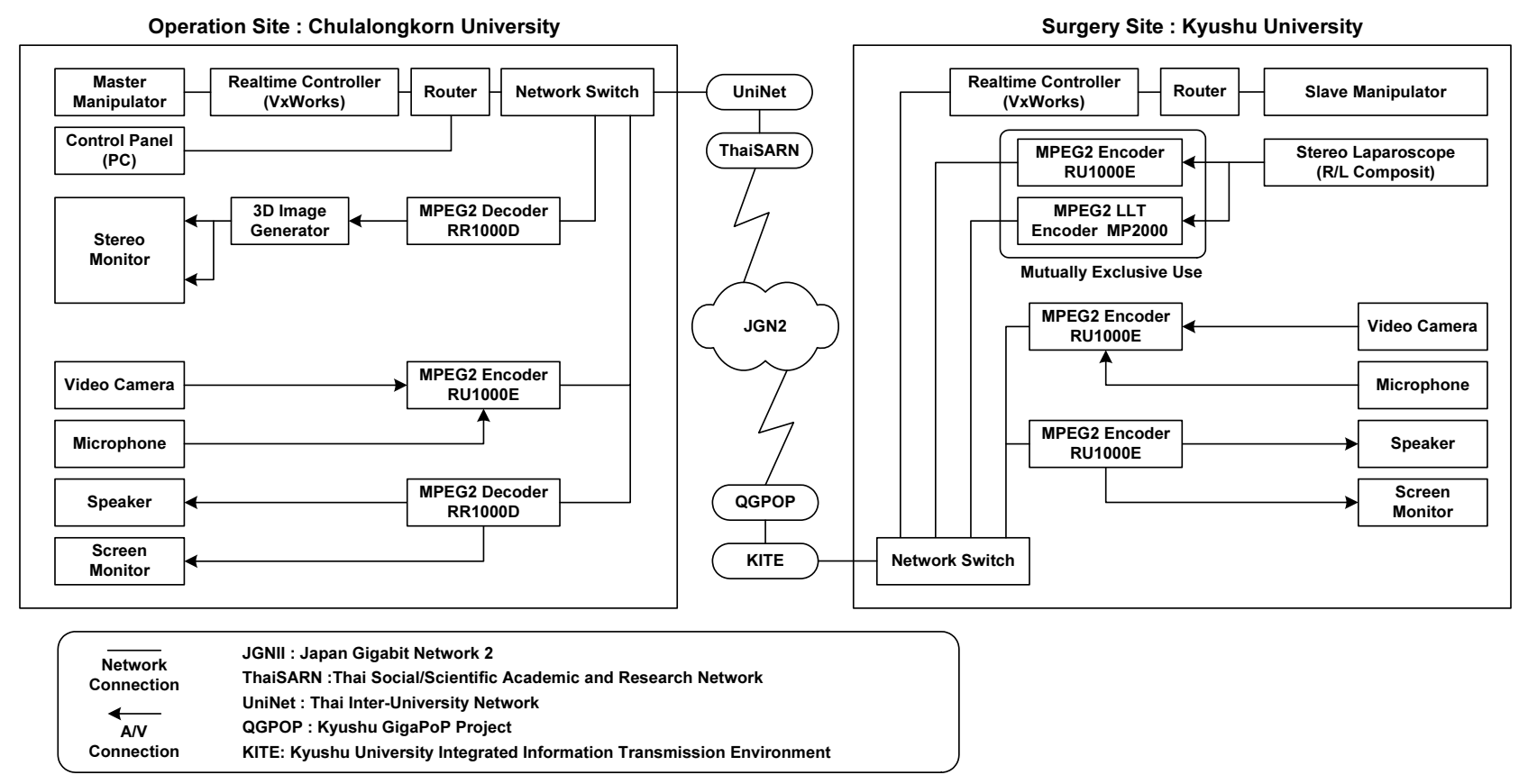

Fig. 5. Overview of the network configuration

\section{EXPERIMENTAL SETUP}

In this experiment, a laparoscopic cholecystectomy on a pig was carried out by the following experimental setup.

\section{A. Experiment facility}

The operation site was located in Chulalongkorn University (Department of Social and Preventive Medicine, Faculty of Medicine, Chulalongkorn University, Bangkok 10330, Thailand), and the surgery site was located in Kyushu University (3-1-1 Maidashi, Higashi-ku, Fukuoka 812-8582, Japan). The direct distance between these sites is approximately $3750 \mathrm{~km}$. The experiment took place from 16:00 in Japan Standard Time (JST).

This experiment was conducted by the trained medical doctors of animal experiments, with the approval of Institute of Laboratory Animals, Faculty of Medical Sciences, Kyushu University.

\section{B. Network configuration}

Fig.5 shows the network configuration of the experiment. From Kyushu University, the transmission path is connected to JGN2, which is an open testbed Internet environment for research and development, through the Kyushu University local area network, KITE (Kyushu University Integrated Information Transmission Environment) and R \& D Internet, QGPOP (Kyushu GigaPOP Project). JGN2 is connected to ThaiSARN (Thai Social/Scientific Academic and Research Network) which is connected to the Chulalongkorn University local area network, ChulaNET through UniNet (Thai Inter-University Network).

Fig.6 shows the data transmission between the operation site and the surgery site. The master and slave manipulators

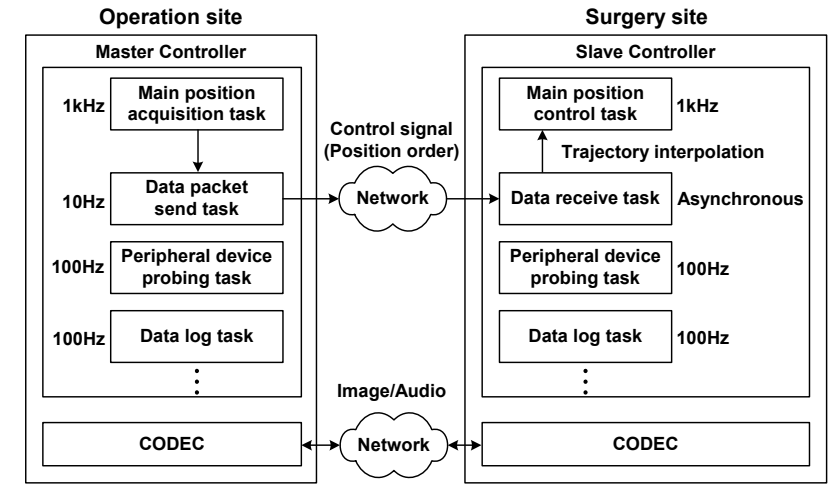

Fig. 6. Data transmission

were controlled by real-time operating system, VxWorks. The control signal ( 80 Byte data) was sent from the master controller to the slave controller at a rate of $10 \mathrm{~Hz}$. The received data on the slave controller is immediately updated to the main position control task within the trajectory interpolation. For the image and audio transmission, MPEG CODECs including the developed low latency CODEC were used. The force information was not fed back in this experiment.

\section{Control signal transmission}

A UDP/IP native socket connection was established for the position control signal transmission. TCP/IP data communication enables a congestion control in order to maintain the stable throughput. However, the congestion control slows the data transmission when the network communication band is not satisfactory provided and it would be a disturbance of real-time tele-operation as a varied time-delay. Therefore, a UDP/IP native socket connection was established for 
TABLE II

DATA TRANSFER BANDWIDTH

\begin{tabular}{l|c}
\hline Transmitted data & Bandwidth \\
\hline From operation site to surgery site: & \\
Image and audio for communication & $4 \mathrm{Mbps}$ \\
Robot control signal & $6 \mathrm{kbps}$ \\
Visual Phone (for maintenance) & $128 \mathrm{kbps}$ \\
From surgery site to operation site: & \\
Image and audio for communication & $2 \mathrm{Mbps}$ \\
Image of laparoscope & $4 \mathrm{Mbps}$ \\
Visual Phone (for maintenance) & $128 \mathrm{kbps}$ \\
\hline total & $10.3 \mathrm{Mbps}$ \\
\hline
\end{tabular}

the position control signal transmission in this experiment. UDP/IP data transmission is well known that it is less reliable than TCP/IP data transmission. Thus, following conditions were set for monitoring the control signal transmission on the slave controller. If an arrival packet was match with the condition(s), the packet data is ignored.

- Order reversal of arrival packets

- Multiple packets arrival in $1 \mathrm{kHz}$ loop

- Anomaly packet size

- Data content damage

\section{Image and audio transmission}

Several kinds of image and audio information were transmitted in this experiment by using hardware MPEG CODECs including the low latency CODEC system. Table II shows the transmitted information.

The low latency CODEC was used for the laparoscopic image transmission. In this experiment, a stereoscopic laparoscope (Shinko Kouki) was used by transmitting right and left eye images as an interlaced image by putting them into odd and even frames. Therefore, the transmitted image resolution was $720 \times 240$. To test the efficiency of the low latency CODEC system, a conventional MPEG encoder RU1000E (NTT Electronics) was also setup and alternatively used.

\section{EXPERIMENTAL RESULT}

A laparoscopic cholecystectomy on a pig was successfully carried out. The completion time of the surgery was about 90 min including setup time, which is roughly equal to a conventional laparoscopic cholecystectomy.

\section{A. Network measurements}

Several network measurements were conducted during the experiment by using network tools as follows.

\section{Traceroute}

The traceroute results in every 5 minuets visualized by 3D Traceroute[19] during the experiment is shown in Fig.7. Between 6-7 hop, the time-delay of approximately $100 \mathrm{~ms}$ was observed. This time-delay occurred by the communication of the backbone routers between Japan and Thailand. From this result, no major variation of network quality was observed.

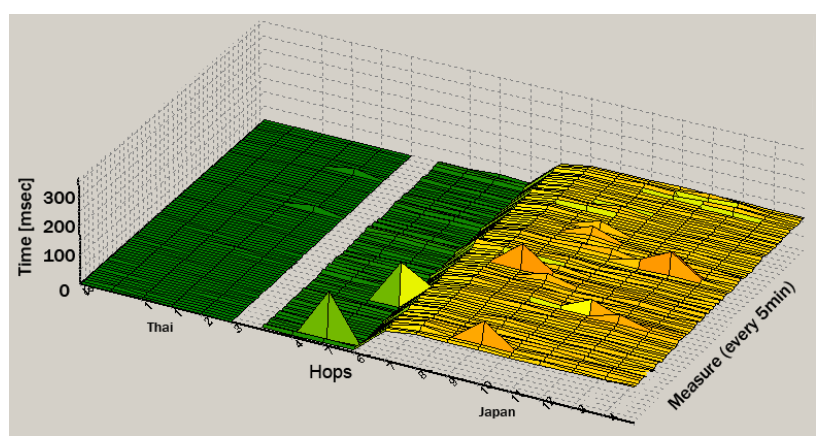

Fig. 7. Network monitoring by 3D Traceroute

\section{$M R T G$}

From the traffic monitoring result on the backbone router of JGN2 (at Bangkok) by using MRTG, the stable traffic flow by the data transmission of this experiment was observed (Fig.8). The amount of monitored traffic corresponded with the used bandwidth in the experiment.

iperf

The measurement result of the network bandwidth using iperf[21] (TCP/IP window size: 0.02 MByte) was approximately 1 Mbps during the experiment (Fig.9). The result revealed that the TCP/IP throughput was narrowed down because of the decrease of TCP window size by the congestion control.

ping

The measurement of round-trip time by using ping was conducted (Fig.10). During the experiment, the 10 packets (same size of robot control signal: 80 Byte) are sent in every 5 minuets (sent in 1 packet/sec). A large amount of timedelay was observed in limited number of packets. However, the result shows the stable time-delay in average. The average time-delay in round-trip was $124.7 \mathrm{~ms}$.

\section{B. Time-delay}

\section{Time-delay of control signal}

From the measurement of round-trip time by ping, the average of time-delay in round-trip was $124.7 \mathrm{~ms}$. TableIV shows the comparison of time-delay between the past experiments. Comparing with the past experiment between Japan and Korea using Internet, the time-delay was increased in this experiment along with the longer distance.

\section{Time-delay of Image and Audio transmission}

The measurements of the image time-delay were conducted by recording loopback images of a stop watch. The measurements were conducted in following 2 cases:

- Normal: encoder-RU1000E, decoder-RR1000D

- Low latency: encoder-MP2000, decoder-RR1000D

From the experimental result, the round-trip time was in average $740.0 \mathrm{~ms}$ by the normal CODEC, and $540.0 \mathrm{~ms}$ by the low latency CODEC. Therefore, using the low latency CODEC system, $200 \mathrm{~ms}$ of time-delay was shortened. 


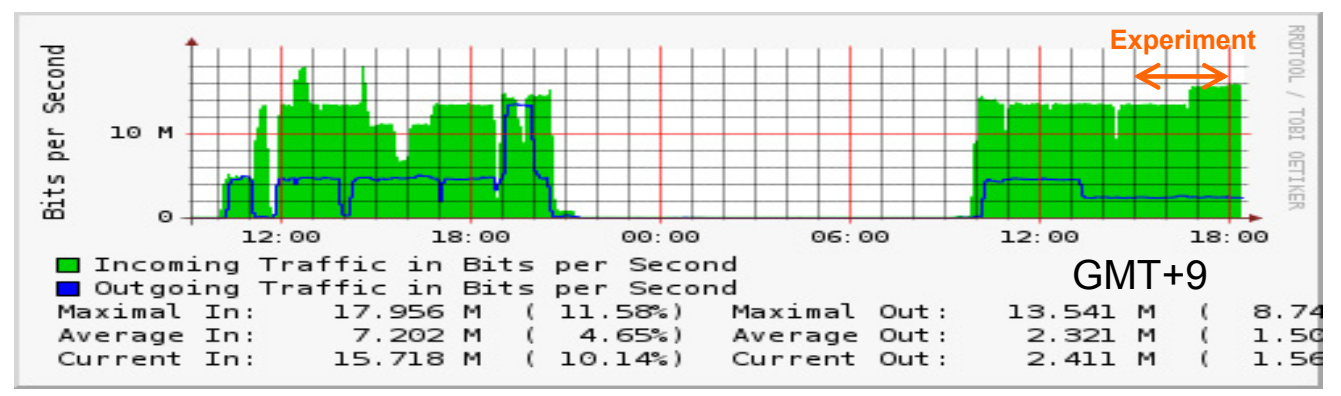

Fig. 8. Traffic monitoring by MRTG on Bangkok backbone router in JST

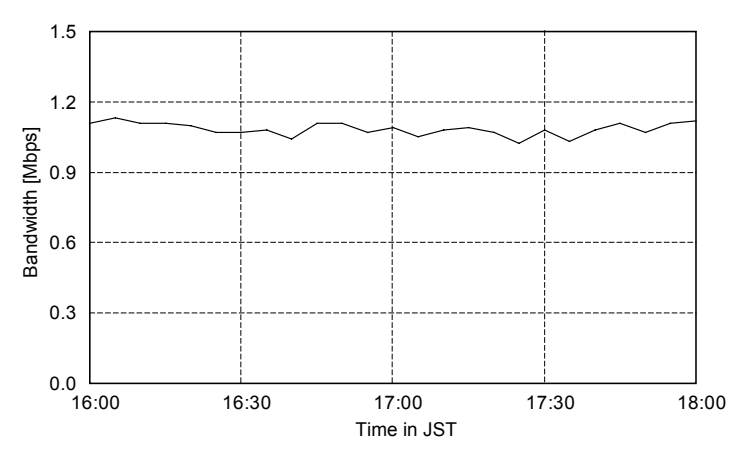

Fig. 9. Network bandwidth measurement by iperf

TABLE III

SENSIBLE TIME-DELAY OF OPERATOR

\begin{tabular}{l|c|c}
\hline Network & Ope. site-Surg. site & Time-delay \\
\hline ISDN(2B+D)x2 & Tokyo-Shizuoka & $540.0 \mathrm{~ms}$ \\
ISDN(23B+D) & Tokyo-Shizuoka & $592.5 \mathrm{~ms}$ \\
APII & Seoul-Fukuoka & $592.5 \mathrm{~ms}$ \\
JGN2-Normal & Bangkok-Fukuoka & $582.4 \mathrm{~ms}$ \\
JGN2-Low latency & Bangkok-Fukuoka & $482.4 \mathrm{~ms}$ \\
\hline
\end{tabular}

\section{Sensible time-delay of operator}

The sensible time-delay of operator in average can be determined by the sum of the master slave data update frequency, the control signal time-delay (in average), the mechanical responsivity of the slave manipulator and the image time-delay (in average). Using the Low latency CODEC system, the time-delay was drastically improved compared with the past experiments. Despite the longer distance, the sensible time delay was $482.4 \mathrm{~ms}$, the smallest value during the past experiments (Table III). Using the normal CODEC, the sensible time-delay was $582.4 \mathrm{~ms}$.

\section{Transmitted image quality}

The transmitted 3D laparoscopic image was sufficiently applicable in practical use. Comparing the transmitted image quality between normal and low latency CODEC, sporadically-occurring block noises were observed in the transmitted image by the low latency CODEC. Using normal CODEC, the block noises were not observed. Therefore, depending on the image condition, the normal and low

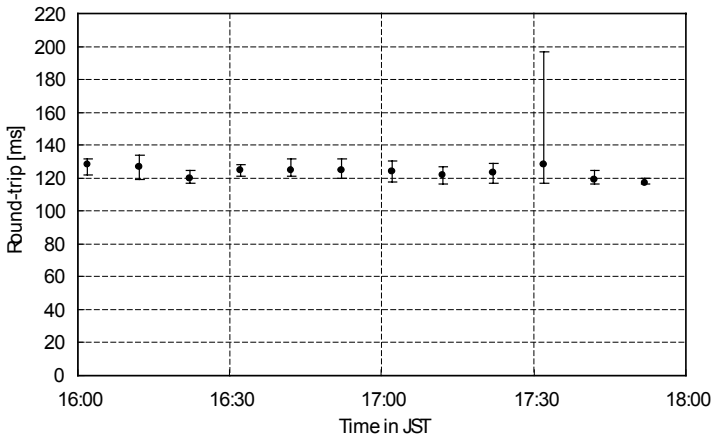

Fig. 10. ping responce (round-trip)
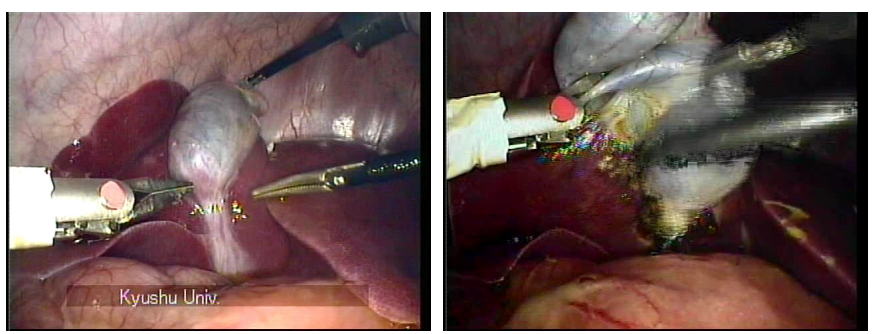

Fig. 11. Transmitted image quality of this experiment (left: normal, Right: low latency (with block noise))

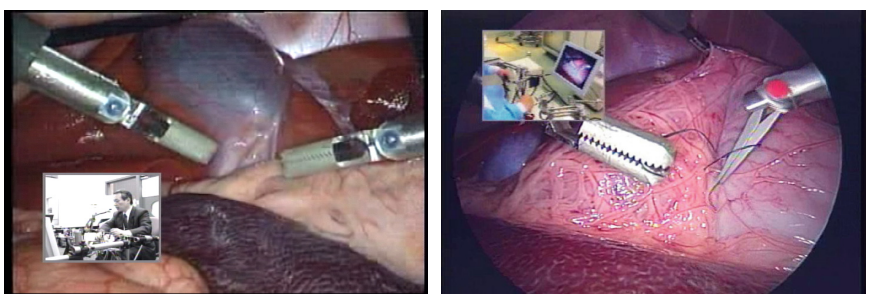

Fig. 12. Image quality of the past experiments (left: Tokyo-Shizuoka by ISDN(2B+D)x2, Right: Japan-Korea by DVTS

latency CODEC were selectively used during the experiment (fig.11).

Using the low latency CODEC, it is important to set the appropriate parameters such as the buffer size for communication on encoder and decoder, the number of frames for inter-frame prediction and the encoding mode (such as a priority configuration between motion and picture quality). On the other hand, the optimized parameters of the CODEC have possibilities of further improvement of the time-delay and image quality of the low latency CODEC system. The 
TABLE IV

NETWORK TIME-DELAY BY PING (ROUND-TRIP)

\begin{tabular}{l|c|c|c|c|c}
\hline Network & Used bandwidth & Operation site - Surgery site & Distance & Hop & Time-delay \\
\hline ISDN(2B+D) & $256 \mathrm{kbps}$ & Tokyo - Shizuoka & $150 \mathrm{~km}$ & - & $99.8 \mathrm{~ms}$ \\
ISDN(23B+D) & $1472 \mathrm{kbps}$ & Tokyo - Shizuoka & $150 \mathrm{~km}$ & - & $35.6 \mathrm{~ms}$ \\
R \& D Internet (APII) & $50 \mathrm{Mbps}$ & Seoul - Fukuoka & $540 \mathrm{~km}$ & 14 & $13.0 \mathrm{~ms}$ \\
R \& D Internet (JGN2) & $10.3 \mathrm{Mbps}$ & Bangkok - Fukuoka & $3750 \mathrm{~km}$ & 15 & $124.7 \mathrm{~ms}$ \\
\hline
\end{tabular}

TABLE V

COMPARISON OF IMAGE TIME-DELAY (ROUND-TRIP)

\begin{tabular}{l|c|c|c|c|c}
\hline Network & Ope.site - Surg. site & Distance & CODEC & Bandwidth & Time-delay \\
\hline ISDN(2B+D) x & Tokyo - Shizuoka & $150 \mathrm{~km}$ & SONY PCS-P500 & $256 \mathrm{kbps}$ & $676.0 \mathrm{~ms}$ \\
ISDN(23B+D) & Tokyo - Shizuoka & $150 \mathrm{~km}$ & NEC TC5000EX100 & $1472 \mathrm{kbps}$ & $785.0 \mathrm{~ms}$ \\
R \& D Internet (APII) & Seoul - Fukuoka & $540 \mathrm{~km}$ & DVTS & $10 \mathrm{Mbps}$ & $871.0 \mathrm{~ms}$ \\
R \& D Internet (JGN2) & Bangkok - Fukuoka & $3750 \mathrm{~km}$ & RU1000E/RR1000D (Normal) & $4 \mathrm{Mbps}$ & $740.0 \mathrm{~ms}$ \\
R \& D Internet (JGN2) & Bangkok - Fukuoka & $3750 \mathrm{~km}$ & MP2000/RR1000D (Low latency) & $4 \mathrm{Mbps}$ & $540.0 \mathrm{~ms}$ \\
\hline
\end{tabular}

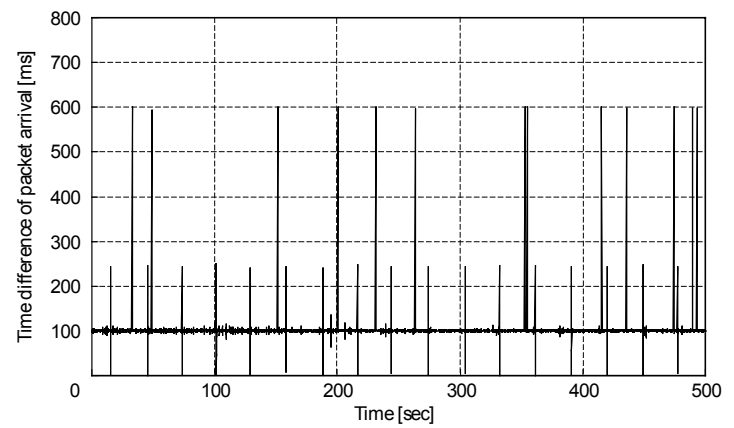

Fig. 13. Time difference of packet arrival by TCP/IP

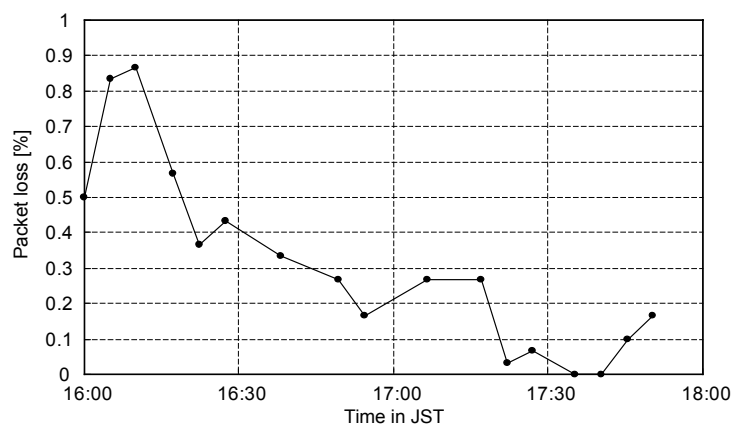

Fig. 15. Packet loss rate by UDP/IP

stabilization of the law latency CODEC image quality is a subject for a further study.

Comparing with the past experiments using different CODEC systems, the image quality was improved from the Japan inland experiments. Comparing the experiment between Japan and Korea, slight image quality deterioration was observed on the transmitted image, because of the MPEG data compression. However, required bandwidth for the transmission was drastically reduced. Furthermore, the time-delay is shortened despite the longer distance.

\section{TCP/IP vs. UDP/IP}

Using a TCP/IP native socket for the control signal transmission, the packets arrived to the slave controller within a varied time-delay, because of the congestion control. Conse-

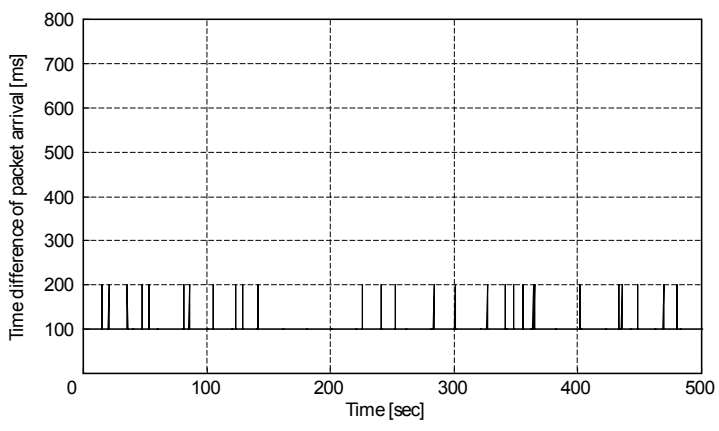

Fig. 14. Time difference of packet arrival by UDP/IP

quently, it was impossible to operate the slave manipulator. Therefore, the congestion control can be a major disturbance of the tele-operation.

Fig. 13 and 14 show the time difference of packet arrival on the slave controller by TCP/IP and UDP/IP respectively. The master controller sends the packets in every $100 \mathrm{~ms}$, thus the slave manipulator is supposed to receive the packets in every $100 \mathrm{~ms}$. However, a varied time-delay was observed on the TCP/IP connection in the range of $600 \mathrm{~ms}$. In contrast, no varied time-delay was observed on the UDP/IP connection. The data $\log$ on the slave controller revealed that the observed $200 \mathrm{~ms}$ of the time difference of packet arrival on UDP/IP was caused by packet loss. Fig. 15 shows the packet loss rate during the experiment using the UDP/IP connection. This did not affect the operation because the packet loss was occurred only sporadically.

From these results, UDP/IP is preferable under the situation, in which the congestion control occurs. However, UDP/IP does not provide the reliability and ordering guarantees that TCP/IP does. Therefore, the safety process that we implemented in the control software (as shown in chap.IV-C) is important to achieve remote surgeries safely.

\section{CONCLUSIONS}

A remote surgery (laparoscopic cholecystectomy) on a pig was successfully performed by using the minimally invasive surgical system between Japan and Thailand over $3750 \mathrm{~km}$. 
- The completion time of the surgery was about 90 min including setup time, which is roughly equal to a conventional laparoscopic cholecystectomy.

- From several network measurements such as traceroute and MRTG, it is confirmed that the data for the experiment was properly transmitted. The result of iperf revealed that the congestion control was occurred on $\mathrm{TCP} / \mathrm{IP}$ communication.

- TCP/IP is not applicable to the critical real-time application such as the remote surgery when the congestion control occurs on the network connection.

- Using UDP/IP, it was possible to carry out the remote surgery. However, the packet loss was observed during the experiment.

- The round-trip time of ping (same packet size as the control signal of the system) in average was $124.7 \mathrm{~ms}$.

- Using the low latency CODEC system, the round-trip time of image in average was $540.0 \mathrm{~ms}$. The required bandwidth for the transmission was drastically reduced and the time-delay was shortened despite the longer distance compared with the past experiments. However, sporadically-occurring block noises were observed in the transmitted image by the low latency CODEC system.

It is not realistic to lay dedicated fiber-optic lines all around the world for remote surgery in terms of cost. Therefore, our research approach with conventional network infrastructures is important for the future wide use of the remote surgery applications. The experimental result positively shows the feasibility of remote surgery using conventional network infrastructures. However, shorter time-delay and stabilized network (no time variation of quality) are desirable for the patient's safety and the surgeon's operability.

In this experiment, the TCP/IP communication was not applicable because of its congestion control. Using the UDP/IP communication, a remote surgery was successfully carried out. However, the safety process should be implemented on the control software. Also the packet loss problem has to be taken care. Most of the time-delay occurs on the image transmission. By using the low latency CODEC system, the sensible time-delay of operator was shortened compared with the past experiments despite of the longer distance. The stabilization of the image of the low latency CODEC system is a subject for a further study. Further improvements of the low latency CODEC system can allow the remote surgery applications to be more realistic and practical.

\section{ACKNOWLEDGMENTS}

The authors gratefully acknowledge reviewer's comments. A part of this research was supported by the University of Tokyo, the 21st century COE program "Mechanical Systems Innovation", and worked in cooperation with Japan Ministry of Internal Affairs and Communications, 2006 Project "Advanced IT Collaboration Experiments for Creating International Info-Communication HUB (a part of the Asia Broadband Program)".

\section{REFERENCES}

[1] J. Marescaux, J. Leroy, M. Gagner, F. Rubino, D. Mutter, M. Vix, S. E. Butner and M. K. Smith, "Transatlantic robot-assisted telesurgery," NATURE, vol.413, no.27, pp.379-380, Sept. 2001.

[2] S. Gary, J. Guthart, and K. Salisbury, "The Intuitive Telesurgery System: Overview and Application," Proc. of IEEE Int. Conf. on Robotics and Automation, pp.618-621, April. 2000.

[3] Intuitive Surgical: http://www.intuitivesurgical.com

[4] U. Seibold, B. Kubler, and G. Hirzinger, "Prototype of Instrument for Minimally Invasive Surgery with 6-Axis Force Sensing Capability," Proc. of IEEE Int. Conf. on Robotics and Automation, pp.498-pp.503, April. 2005.

[5] M. Hashizume, T. Yasunaga, K. Konishi, S. Ieiri, K. Tanoue, K. Kishi, H. Nakamoto and D. Ikeda, "MR image-guided surgical robotic system." Int. Journal of Computer Assisted Radiology and Surgery, vol.1, pp.203-205, June. 2006.

[6] K. Ikuta, H. Ichikawa, K. Suzuki and D. Yajima, "Multi-degree of Freedom Hydraulic Pressure Driven Safety Active Catheter," Proc. of Int. Conf. Robotics and Automation, pp.4161-4166, May. 2006.

[7] K. Ikuta, T. Kato and S. Nagata, "Micro active forceps with optical fiber scope for intra-ocular microsurgery," Proc. of Micro Electro Mechanical Systems, pp.456-461, Feb. 1996.

[8] R. Kumar, P. Berkelmann, P. Gupta, A. Barnes, P. S. Jensen, L. L. Whitcomb and R. H. Taylor, "Preliminary Experiments in Cooperrative Human/Robot Force Control for Robot Assisted Microsurgical Manipulation," Proc. of IEEE Int. Conf. on Robotics Automation, pp.610-617, April. 2000.

[9] T. Hasuo, G. Ogura, I. Sakuma, E. Kobayashi, H. Iseki and R. Nakamura, "Development of bending and grasping manipulator for multi degrees of freedom ultrasonically activated scalpel." Int. Journal of Computer Assisted Radiology and Surgery, vol.1, pp.222-226, June. 2006.

[10] H. Yamashita, K. Matsumiya, K. Masamune, H. Liao, T. Chiba and T. Dohi, "Two-DOFs bending forceps manipulator of $3.5-\mathrm{mm}$ diameter for intrauterine fetus surgery: feasibility evaluation." Int. Journal of Computer Assisted Radiology and Surgery, vol.1, pp.218-222, June. 2006.

[11] H. Song, J. Chung and J. Lee, "The Dexterous human-arm like manipulator for Laparoscopic Surgery," Proc. of World Congress on Medical Physics and Biomedical Eng, pp.2959-2963, Aug. 2006.

[12] Y. Iwamori, J. Okamoto and M. G. Fujie, "Multi-DOF Forceps Manipulator for an Approach to the dorsal aspect of an Organ," Proc. of Asian Int. Conf. on Computer-Aided Surgery, pp.4022-4025, Sept. 2006.

[13] J. Arata, H. Takahiro, P. Pitakwatchara, S. Warisawa, K. Konishi, K. Tanoue, S. Ieiri, S. Shimizu, N. Nakashima, K. Okamura, Y. S. Kim, S. M. Kim, J. S. Hahm, M. Hashizume and M. Mitsuishi, "A remote surgery experiment between Japan-Korea using the minimally invasive surgical system," Proc. of Int. Conf. on Robotics and Automation, pp.257-262, May. 2006.

[14] J. Arata, Ko. Tanaka, Ka. Tanaka, S. Warisawa, M. Hashizume and M. Mitsuishi,"Remote Robotic Surgery System for a Laparoscopy," Proc. of the Japan-USA Symposium on Flexible Automation, JS020, July. 2004.

[15] J. Arata, M. Mitsuishi, S. Warisawa, K. Tanaka, T. Yoshizawa and M. Hashizume, "Development of a dexterous minimally-invasive surgical system with augmented force feedback capability," Proc. of Int. Conf. on Intelligent Robots and Systems, pp.3738-3743, Aug. 2005.

[16] M. Mitsuishi, J. Arata, K. Tanaka, M. Miyamoto, T. Yoshidome, S. Iwata, S. Warisawa and M. Hashizume, "Development of a Remote Minimally-Invasive Surgical System with Operational Environment Transmission Capability," Proc. of Int. Conf. on Robotics and Automation, pp.2663-2670, Sept. 2003.

[17] Japan Gigabit Network 2 (JGN2): http://www.jgn.nict.go.jp/e/index.html

[18] Asia Broadband Program (Asia-BB): http://www.asia-bb.net/en/index.html

[19] 3D traceroute:

[20] MRTG: http://www.d3tr.de/

[21] iperf: http://people.ee.ethz.ch/ oetiker/webtools/mrtg/

http://dast.nlanr.net/Projects/Iperf/ 